\title{
Dipeptidyl peptidase 4 (DPP-4) is expressed in mouse and human islets and its activity is decreased in human islets from individuals with type 2 diabetes
}

\author{
Bilal A. Omar • Liu Liehua • Yuchiro Yamada • \\ Yutaka Seino • Piero Marchetti • B. Ahrén
}

Received: 4 March 2014 / Accepted: 28 May 2014 / Published online: 18 June 2014

(C) Springer-Verlag Berlin Heidelberg 2014

\begin{abstract}
Aims/hypothesis Inhibition of the enzyme dipeptidyl peptidase 4 (DPP-4), which cleaves and inactivates glucagon-like peptide 1 (GLP-1), is a glucose-lowering strategy in type 2 diabetes. Since DPP-4 is a ubiquitously distributed enzyme, we examined whether it is expressed in islets and whether an islet effect to inhibit DPP-4 may result in stimulated insulin secretion.

Methods We investigated DPP-4 expression and activity in the islets of mouse models of obesity as well as human islets from non-diabetic and type 2 diabetic donors. We further investigated whether inhibition with DPP-4 inhibitors could promote insulin secretion via islet GLP-1 in isolated islets. Results DPP-4 was readily detected in mouse and human islets with species-specific cellular localisation. In mice, DPP-4 was expressed predominantly in beta cells, whereas in humans it was expressed nearly exclusively in alpha cells.
\end{abstract}

Electronic supplementary material The online version of this article (doi:10.1007/s00125-014-3299-4) contains peer-reviewed but unedited supplementary material, which is available to authorised users.

B. A. Omar $(\bowtie) \cdot$ B. Ahrén

Department of Clinical Sciences, Biomedical Center, C11,

Lund University, SE22184 Lund, Sweden

e-mail: bilal.omar@med.lu.se

L. Liehua

The First Affiliated Hospital of Sun Yat-sen University,

Guangzhou, China

\section{Y. Yamada}

Department of Endocrinology, Diabetes and Geriatric Medicine,

Graduate School of Medicine, Akita University, Akita, Japan

Y. Seino

Kensai Electric Power Hospital, Osaka, Japan

P. Marchetti

Department of Endocrinology and Metabolism, University of Pisa,

Pisa, Italy
DPP-4 activity was significantly increased in islets from dietinduced obese mice compared with mice fed a control diet. In humans, DPP-4 activity was significantly lower in islets from type 2 diabetic donors than in non-diabetic donors. In human islets, there was a significant positive correlation between DPP-4 activity and insulin secretory response to $16.7 \mathrm{mmol} / 1$ glucose. Treatment of mouse islets with the DPP-4 inhibitors, NVPDPP728 and vildagliptin, resulted in a significant potentiation of insulin secretion in a GLP-1-dependent manner, as this was inhibited by the GLP-1 receptor antagonist, Exendin (9-39), and was retained in glucose-dependent insulinotropic polypeptide (GIP) receptor-deficient mice but lost in mice lacking GLP-1 receptors or both incretin receptors. Human islets treated with the DPP-4 inhibitor, vildagliptin, showed increased secretion of insulin and intact GLP-1.

Conclusions/interpretation We conclude that DPP-4 is present and active in mouse and human islets, is regulated by the disease state, and that inhibition of islet DPP-4 activity can have direct effects on islet function. Inhibiting islet DPP-4 activity may therefore contribute to the insulin-secretory and glucose-lowering action of DPP-4 inhibition.

Keywords GLP-1 · Insulin secretion · Islets of Langerhans · Obesity · Type 2 diabetes

$\begin{array}{ll}\text { Abbreviations } \\ \text { DIRKO } & \text { Double incretin receptor knockout } \\ \text { DPP-4 } & \text { Dipeptidyl peptidase } 4 \\ \text { GIP } & \text { Glucose-dependent insulinotropic polypeptide } \\ \text { GLP-1 } & \text { Glucagon-like peptide } 1 \\ \text { HFD } & \text { High-fat diet } \\ \text { ND } & \text { Normal chow diet } \\ \text { PC1/3 } & \text { Prohormone convertase } 1 / 3 \\ \text { SDF-1 } & \text { Stromal cell-derived factor-1 }\end{array}$




\section{Introduction}

The incretin hormones, glucose-dependent insulinotropic polypeptide (GIP) and glucagon-like peptide 1 (GLP-1), are insulinotropic factors secreted from the intestine in response to nutrient intake [1]. The intact, active form of the incretin hormones are short-lived peptides with half-lives of 2-7 min in humans [2]. The short half-life of the incretins is due to their rapid degradation by the serine protease, dipeptidyl peptidase 4 (DPP-4) [3]. DPP-4 is abundantly expressed by vascular endothelial cells and is present in the circulation in both membrane-bound and soluble forms [4]. Inhibition of DPP-4 results in higher circulating levels of intact GLP-1 and GIP and increased insulin secretion [5]. Consequently, numerous pharmacological DPP-4 inhibitors are being used in clinical practice for the treatment of type 2 diabetes [6].

Recent studies have suggested that DPP-4 inhibition exerts local glucose-lowering effects that are independent of inhibition of circulating DPP-4 activity. Thus, oral administration of a low dose of DPP-4 inhibitor to mice reduced glucose without inhibiting the circulating DPP-4 activity [7, 8]. This would suggest that local DPP-4 activity is also important for the glucose-lowering action of DPP-4 inhibitors. In addition, numerous studies have demonstrated that GLP-1 is secreted, not only in the intestine, but also in the pancreatic islets due to alternative processing of proglucagon [9-13]. Regulation of islet GLP-1 by glucose, cytokines, chemokines and the diabetic state has been demonstrated, and it has been shown to be increased in islets of type 2 diabetic humans [11-14]. This would make it possible that DPP-4 inhibitors may also work through a direct islet action, provided that islets express DPP4 with DPP-4 activity. However, the regulation of islet GLP-1 by DPP-4 has not been investigated to date. This study therefore examined the expression, cellular localisation, activity and functional consequences of DPP-4 in islets from multiple mouse models and healthy and type 2 diabetic human donors.

\section{Methods}

Materials Human pancreatic biopsy samples were obtained from five non-diabetic donors and fixed in formaldehyde before paraffin embedding and tissue sectioning, with approval from the local ethics committee in Pisa. Human islets were obtained from cadaver donors courtesy of the Nordic Network for Clinical Islet Transplantation (www.nordicislets.org; accessed 1 March 2014), Uppsala University, with appropriate ethics permission obtained from the regional ethics committees in Lund and Uppsala.

Animals Six-week-old male and female C57BL6/JBomTac mice were purchased from Taconic Europe (Skensved, Denmark). For studies of diet-induced obesity, mice were fed ad libitum with either normal control chow (ND) or a high-fat diet (HFD) (D12492 Research Diets, New Brunswick, NJ, USA) containing $60 \% \mathrm{~kJ}$ from fat. Glucagon receptor-deficient mice $\left(\mathrm{Gcgr}^{-/}\right)$were derived as previously described [15]. Double incretin receptor knockout (DIRKO) mice were derived as previously described [16]. Single GIP receptor- and GLP-1 receptor-deficient mice were obtained by crossing wild-type C57BL6 mice with DIRKO mice and pairing the subsequent heterozygotes.

Immunohistochemistry Human pancreatic sections were obtained as described above. Formaldehyde-fixed, paraffinembedded mouse pancreatic sections $(5 \mu \mathrm{m}$ thick) were obtained from mice fed with ND or HFD (for 16 weeks) as well as $\mathrm{Gcgr}^{-/-}$mice. After dewaxing of the sections, the antibodybinding epitopes of DPP-4 were retrieved by heating in a water bath at $95^{\circ} \mathrm{C}$ for $20 \mathrm{~min}$ in sodium citrate buffer (10 mmol/1 sodium citrate, $0.05 \%$ Tween $20, \mathrm{pH} 6.0$ ). Sections were incubated overnight at $4{ }^{\circ} \mathrm{C}$ with primary antibodies against mouse DPP-4 (polyclonal goat anti-mouse DPP-4/CD26 antibody; R\&D Systems, Minneapolis, MN, USA), human DPP-4 (polyclonal goat anti-human DPP-4 antibody; R\&D Systems), insulin (polyclonal guinea pig anti-insulin antibody; EuroProxima, Arnhem, the Netherlands), glucagon (monoclonal mouse anti-glucagon antibody; Abcam, Cambridge, UK), amidated GLP-1 (monoclonal

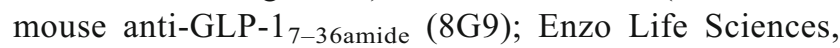
Farmingdale, NY, USA) and somatostatin (polyclonal rabbit anti-somatostatin antibody; a gift from Dr Eva Ekblad, Lund University, Lund, Sweden, originally from Dr Jens J. Holst, University of Copenhagen, Copenhagen Denmark) at 1:200, 1:200, 1:2,000, 1:500 and 1:3,000 dilution, respectively. Specificity of the DPP-4 antibody was validated by preblocking with human CD26 peptide (Abcam). The fluorescent secondary antibodies used were: polyclonal donkey anti-goat (Alexa Fluor 488 conjugated; Molecular Probes, Eugene, OR, USA) for mice/human DPP-4; polyclonal rabbit anti-guinea pig (DyLight 594 conjugated; Abcam) for insulin; polyclonal donkey anti-mouse (Alexa Fluor 594 conjugated; Abcam) for glucagon; and polyclonal goat anti-rabbit (Alexa Fluor 546 conjugated; Abcam) for somatostatin. All of the secondary antibodies were diluted 1:200. Fluorescence images were captured with a Carl Zeiss LSM 780 confocal microscope with Zen imaging software.

Isolation of mouse and human islets Human islets were isolated from pancreases from non-diabetic and type 2 diabetic organ donors by collagenase digestion as previously described [17] and cultured in CMRL 1066 medium (ICN Biomedicals, Costa Mesa, CA, USA) supplemented with $10 \mathrm{mmol} / 1$ HEPES, $2 \mathrm{mmol} / \mathrm{l}$ L-glutamine, $50 \mu \mathrm{g} / \mathrm{ml}$ gentamicin, $0.25 \mu \mathrm{g} / \mathrm{ml}$ Fungizone (Gibco, Gaithersburg, MD, USA), $20 \mu \mathrm{g} / \mathrm{ml}$ ciprofloxacin (Bayer Healthcare, Leverkusen, 
Germany) and $10 \mathrm{mmol} / 1$ nicotinamide at $37^{\circ} \mathrm{C}\left(5 \% \mathrm{CO}_{2}\right)$ for 1-5 days before handpicking and the determination of DPP-4 activity. Mouse islets were isolated by collagenase digestion and handpicked in an inverted microscope. Batches of freshly isolated islets were preincubated in HEPES balanced salt solution containing $125 \mathrm{mmol} / 1 \mathrm{MgCl}_{2}, 25 \mathrm{mmol} / \mathrm{l} \mathrm{HEPES}$ (pH 7.4), $5.6 \mathrm{mmol} / 1$ glucose and $0.1 \%$ fatty acid-free BSA (Boehringer Mannheim, Mannheim, Germany) for $60 \mathrm{~min}$ before insulin secretion experiments.

Analysis of gene expression Gene expression analysis was carried out by microarray on cDNA from islets of 23 type 2 diabetic donors and 23 non-diabetic donors matched for age, sex and BMI, using the Affymetrix GeneChip Human Gene 1.0 ST whole-transcript assay as previously described [18, 19]. The data were summarised and normalised with the robust multi-array analysis method using the Expression Console software package (Affymetrix, Santa Clara, CA, USA). The full dataset is available on the Entrez GEO database with accession number GSE54279.

Glucose-stimulated insulin secretion Insulin secretion in human islets was determined with islet perifusion and static islet incubation. Shortly after isolation from human donors, islets were subjected to glucose perifusion experiments as previously described [20]. Briefly, 20 islets were perifused with low $(1.67 \mathrm{mmol} / \mathrm{l})$ glucose for $40 \mathrm{~min}$ before perifusion with high $(16.7 \mathrm{mmol} / \mathrm{l})$ glucose for $40 \mathrm{~min}$ and returning to baseline $1.67 \mathrm{mmol} / \mathrm{l}$ glucose perifusion. The stimulatory index was calculated as the ratio of insulin released during high-glucose perifusion to the insulin released during low-glucose perifusion [21]. For static incubations, human or mouse islets were isolated as described above, then incubated in groups of three in $200 \mu \mathrm{l}$ of the buffer described above with 2.8 or $16.7 \mathrm{mmol} / \mathrm{l}$ glucose in the presence or absence of 100 or 1,000 nmol/1 NVPDPP728 (Tocris Biosciences, Bristol, UK) or 100,500 or $1,000 \mathrm{nmol} / 1$ vildagliptin (gift from Novartis Pharmaceutical, East Hannover, NJ, USA).

Intact GLP-1 secretion from human islets Human islets were obtained as described above and incubated in batches of 40 islets per condition for $24 \mathrm{~h}$. After the incubations, the supernatant fractions were removed, and the DPP-4 inhibitor, diprotin $\mathrm{A}$, was added to prevent degradation of the intact peptide.

Assay of DPP-4 activity DPP-4 activity in islets and incubation media was determined as previously described with GlyPro p-nitroanilide as the substrate [22]. Briefly, islets were isolated as above and disrupted by sonication in $100 \mu \mathrm{l}$ buffer containing $50 \mathrm{mmol} / \mathrm{l} \mathrm{N}$-[tris(hydroxymethyl)methyl]-2aminoethanesulfonic acid (TES), $2 \mathrm{mmol} / \mathrm{l} \mathrm{EGTA,} 1 \mathrm{mmol} / 1$ EDTA, $250 \mathrm{mmol} / 1$ sucrose and $40 \mathrm{mmol} / \mathrm{l}$ phenyl phosphate,
pH 7.4. Then $20 \mu$ sonicate or medium was incubated with $100 \mu 11 \mathrm{mmol} / \mathrm{l} \mathrm{Gly}$-Pro p-nitroanilide for $60 \mathrm{~min}$ at $37^{\circ} \mathrm{C}$. The amount of p-nitroaniline liberated during $60 \mathrm{~min}$ was compared with a $1 \mathrm{mmol} / \mathrm{l}$ nitroaniline standard.

Biochemical assays Insulin secretion was determined with mouse and human ELISA (Mercodia, Uppsala, Sweden). Human intact GLP-1 (7-36 amide and 7-37) was determined by an ELISA that has no detectable cross reactivity with glucagon and detects intact GLP-1 in mammalian species (Millipore, Billerica, MA, USA).

Statistical analyses Data are presented as mean \pm SEM unless otherwise indicated. Correlation analysis was performed with Spearman's correlation test. For mouse islet experiments, differences between groups were determined using Student's unpaired $t$ test. For human islet experiments, differences between treatment groups were determined using paired $t$ test. For all analyses, statistical significance was defined as $p<0.05$. Analyses were carried out using the Prism 6.0 software package (Graphpad, San Diego, CA, USA).

\section{Results}

DPP-4 is expressed in human and mouse islets in a cell-and species-specific manner Fluorescent immunostaining of pancreatic tissue sections from non-diabetic human donors showed abundant DPP-4 expression in islets and vessels (Fig. 1a-c). Co-staining with glucagon, insulin or somatostatin antibodies confirmed that the expression was nearly exclusively in alpha cells (Fig. 1a) with little to no expression in beta cells (Fig. 1b) and no expression in delta cells (Fig. 1c). Using confocal microscopy, we determined that the localisation of DPP-4 within alpha cells appeared to be in compartments distinct from the glucagon granules (Fig. 1a, inset). The expression of DPP-4 was also determined in multiple mouse models. In normal-weight C57BL6 mice, DPP-4 was readily detected in islets and vessels, as in humans (Fig. 2a, b). However, mouse islets expressed DPP-4 primarily in the beta cells (Fig. 2b), with weaker expression in the alpha cells (Fig. 2a). There was no colocalisation of DPP-4 and somatostatin immunoreactivity in normal C57BL6 islets (data not shown). Confocal microscopy of normal mouse islets suggested that DPP-4 expression in the beta cell is in compartments distinct from the insulin granules (Fig. 2b). In mice chronically fed an HFD, DPP-4 was readily detected in islets and strongly expressed in beta cells (Fig. 2a). Similar to NDfed mice, there were few alpha cells that coexpressed DPP-4 and glucagon (Fig. 2b). To compare the cell specificity of DPP-4 expression in mouse islets, we used glucagon receptor-deficient mice, a mouse model of alpha cell 

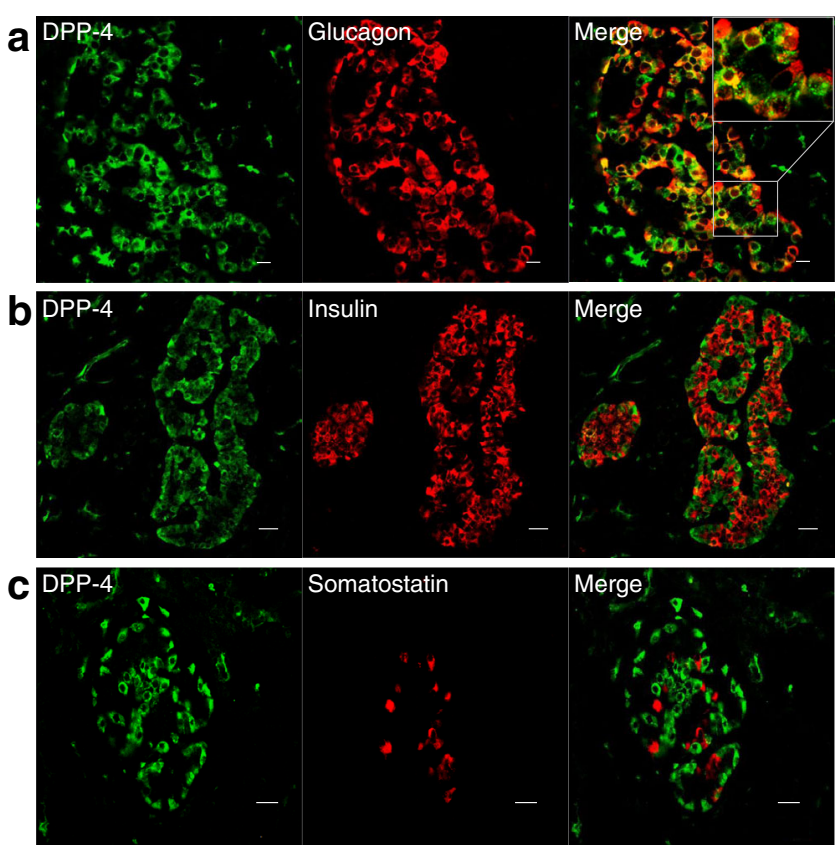

Fig. 1 DPP-4 protein localisation in human islets from non-diabetic donors. Representative confocal microscope images showing cellular localisation of DPP-4 staining and colocalisation with (a) glucagon staining in alpha cells while there was no colocalisation in (b) insulinor (c) somatostatin-stained cells. Images are representative of five nondiabetic donors. Scale bar, $20 \mu \mathrm{m}$

hyperplasia. Glucagon receptor-deficient $\left(\mathrm{Gcgr}^{--}\right)$mice displayed large islets with hyperplastic alpha cells as previously described $[15,23]$. Similar to ND- and HFD-fed C57BL6 mice, $\mathrm{Gcgr}^{-1-}$ mouse islets displayed abundant staining for DPP-4, with the predominance of immunostaining in the beta cells (Fig. 2b). Colocalisation of glucagon and DPP-4 was rare, despite the abundance of alpha cells in islets of $\mathrm{Gcgr}^{-1-}$ mice (Fig. 2a). In addition, amidated GLP-1 was readily detectable in alpha cells from both HFD and $\mathrm{Gcgr}^{-1-}$ mice (electronic supplementary material [ESM] Fig. 1).

Islet DPP4 gene expression does not differ between type 2 diabetic and non-diabetic donors Gene expression as determined by microarray was carried out on a total of 132 donors from the LUDC human tissue laboratory. A subset of the data containing all type 2 diabetic donors $(n=23)$ and an equal number of age-, sex- and BMI-matched controls was analysed. As can be seen in Fig. 3, there was no significant difference in the gene expression level of DPP4 in islets between type 2 diabetic and non-diabetic donors.

Islet DPP-4 activity is increased in obese mice and decreased in type 2 diabetic humans With the establishment of the expression of DPP-4 in the islets of mice and humans, we determined the level of activity of DPP-4. DPP-4 activity was detectable in mouse islet lysates, albeit at a lower level than in plasma (Fig. 4a). In obese mice chronically fed an HFD, DPP4 activity in the islet lysates was significantly increased (Fig. 4b). DPP-4 activity was also detected in both nondiabetic and type 2 diabetic human donors. There was a significant reduction in DPP-4 activity in islets from type 2 diabetic donors compared with non-diabetic donors (Fig. 4c). In human islets, there was a significant positive correlation between DPP-4 activity and glucose-stimulated insulin secretion, as determined by the fold increase in insulin secretion from 1.67 to $16.7 \mathrm{mmol} / \mathrm{l}$ glucose (Fig. 4d). We were also able to observe a trend towards a positive correlation between DPP-4 activity and insulin secretion at $16.7 \mathrm{mmol} / \mathrm{l}$ glucose in mouse islets $(r=0.600, p=0.09)$ (ESM Fig. 2).

Inhibition of DPP-4 activity in islets results in increased insulin and intact GLP-1 secretion Mouse islets were
Fig. 2 DPP-4 protein localisation in mouse islets. Representative confocal microscopy images from $\mathrm{ND}, \mathrm{HFD}$ and $\mathrm{Gcgr}^{-/-}$mice stained for DPP-4 and (a) glucagon or (b) insulin. Note the predominance of DPP-4 staining in insulin-stained beta cells. Scale bar, $20 \mu \mathrm{m}$
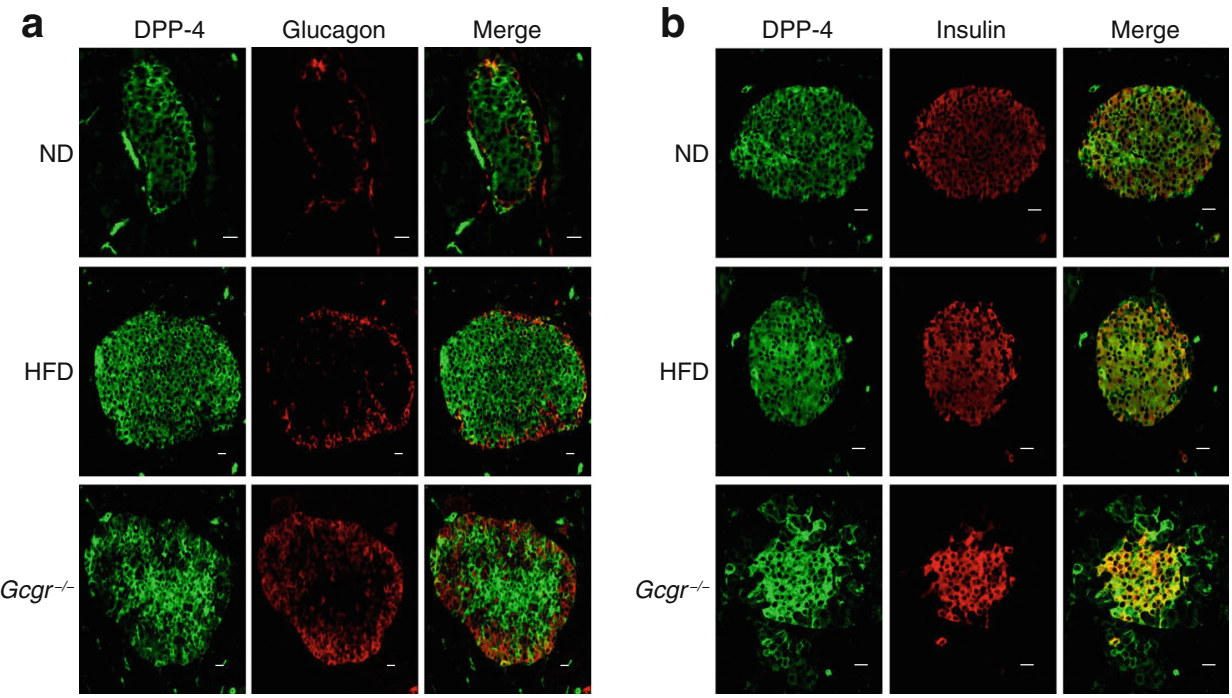


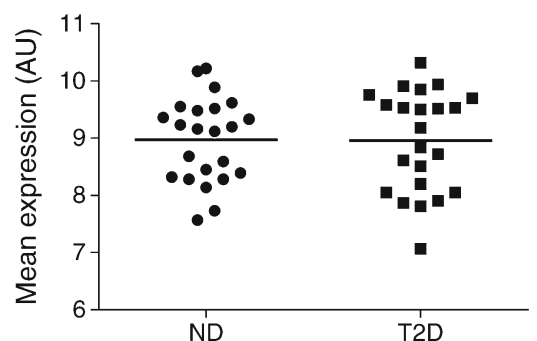

Fig. $3 D P P 4$ gene expression in human islets. Microarray gene expression of DPP4 in pancreatic islets from 23 type 2 diabetic (T2D) human donors and 23 age-, sex- and BMI-matched non-diabetic donors. Microarray data were normalised with robust multi-array analysis. AU, arbitrary units

incubated with low or high glucose in the presence or absence of the DPP-4 inhibitor, NVPDPP728 or vildagliptin. Both DPP-4 inhibitors significantly potentiated glucose-stimulated insulin secretion at $16.7 \mathrm{mmol} / 1$ glucose, and this effect was inhibited by the GLP-1 receptor antagonist, Exendin (9-39) (Fig. 5a, b). As Exendin (9-39) has been shown to have inverse agonist properties in addition to GLP-1 receptor antagonistic properties [24], and to determine whether the DPP4-potentiated insulin secretion was due to islet GLP-1, GIP or both, we used mice singly deficient in the GIP receptor or GLP-1 receptor or mice doubly deficient in the incretin receptors (DIRKO). The DPP-4 inhibitor, NVPDPP728, significantly potentiated glucose-stimulated insulin secretion in
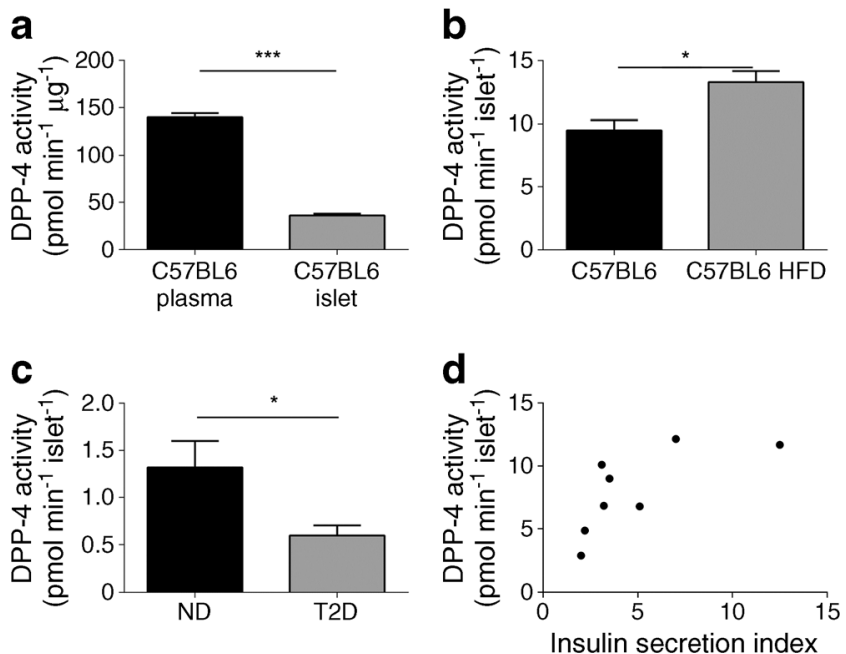

Fig. 4 DPP-4 activity is detectable in mouse and human islets and correlates with insulin secretion. (a) DPP-4 activity in C57BL6 mouse islet ( 200/mouse) lysates and plasma expressed as $\mathrm{pmol} \mathrm{h}^{-1}$ ( $\mu \mathrm{g}$ total protein $)^{-1}$ ( $n=4-5$ per group). (b) DPP-4 activity in islet lysates $(\sim 200$ 400 /mouse) from mice fed ND or HFD for 10 months expressed as pmol min ${ }^{-1}$ islet $^{-1}$ ( $n=5-7$ per group). (c) DPP-4 activity in frozen human islet lysates $(2,000-3,000$ islet equivalents per donor) expressed as pmol $\mathrm{min}^{-1}$ islet $^{-1}$ ( $n=5$ donors per group). T2D, type 2 diabetic donor. (d) Relationship between islet DPP-4 activity and insulin secretion in human islets from diabetic and non-diabetic donors. DPP-4 activity in fresh human islet lysates (100-250 islets per donor) plotted against the ratio of insulin secretion during islet perifusion at $16.7 \mathrm{mmol} / \mathrm{l}$ and $1.67 \mathrm{mmol} / 1$. Spearman $r=0.7619, p=0.0318, n=8$. ${ }^{*} p<0.05$, $* * * p<0.001$
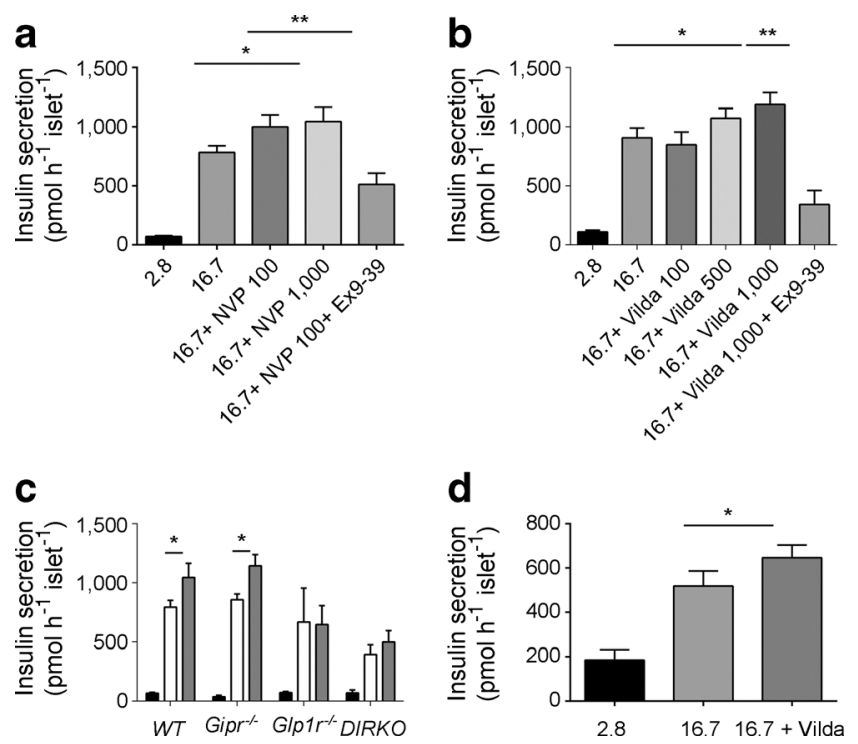

Fig. 5 DPP-4 inhibitors potentiate glucose-stimulated insulin secretion in a GLP-1-dependent manner. Insulin secretion in islets from wild-type C57BL6 female mice incubated with 2.8 or $16.7 \mathrm{mmol} / 1$ glucose with or without the DPP-4 inhibitors (a) NVPDPP728 (NVP; $100 \mathrm{nmol} / \mathrm{l}$ ) or (b) vildagliptin (Vilda; $1,000 \mathrm{nmol} / \mathrm{l}$ ) for $1 \mathrm{~h}$ with or without co-incubation with the GLP-1 receptor antagonist exendin 9-39 (100 nmol/1), expressed as pmol $\mathrm{h}^{-1}$ islet $^{-1}$. $n=10-24$ per condition. (c) Insulin secretion in wildtype, $\mathrm{Gipr}^{-1-}, \mathrm{Glplr}^{-/-}$or DIRKO mouse islets incubated with 2.8 and $16.7 \mathrm{mmol} / 1$ glucose with or without NVPDPP728 (1,000 nmol/1) for $1 \mathrm{~h}$. $n=3-19$ per group. (d) Insulin secretion in human islets incubated with 2.8 and $16.7 \mathrm{mmol} / 1$ glucose with or without vildagliptin (Vilda; 100 $500 \mathrm{nmol} / \mathrm{l})$ for 2 h. $n=4{ }^{* *} p<0.01 ;{ }^{*} p<0.05$

islets from wild-type and $\mathrm{Gipr}^{-/-}$but not in $\mathrm{Glplr}^{-/-}$or DIRKO islets (Fig. 5c). In human islets from non-diabetic individuals, vildagliptin significantly potentiated glucosestimulated insulin secretion (Fig. 5d). The maximally effective dose of vildagliptin varied slightly between individual donors, with three showing maximum potentiation at $500 \mathrm{nmol} / 1$ and one showing maximum potentiation at $100 \mathrm{nmol} / \mathrm{l}$.

The effect of DPP-4 inhibition on GLP-1 secretion from human islets was determined using vildagliptin. Vildagliptin significantly potentiated secretion of intact GLP-1 during a $24 \mathrm{~h}$ incubation at both 2.8 and $16.7 \mathrm{mmol} / \mathrm{l}$ glucose (Fig. 6). There was no significant difference between secretion of intact

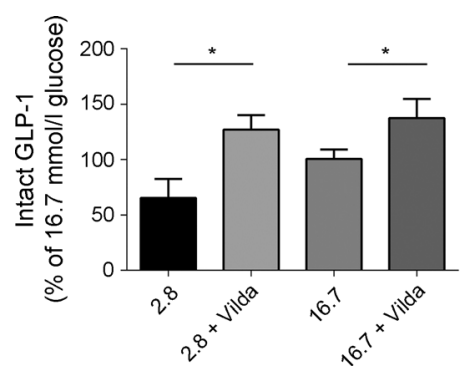

Fig. 6 GLP-1 secretion from human islets is enhanced by the DPP-4 inhibitor, vildagliptin. Intact GLP-1 secreted into medium from incubations of human islets (50 per donor) with 2.8 or $16.7 \mathrm{mmol} / \mathrm{l}$ glucose for $24 \mathrm{~h}$ in the absence or presence of $1,000 \mathrm{nmol} / \mathrm{l}$ vildagliptin (Vilda). $n=4$ 5 per condition. ${ }^{*} p<0.05$ 
GLP-1 at 2.8 and $16.7 \mathrm{mmol} / 1$ glucose in these individual donors.

\section{Discussion}

We describe the expression and activity of DPP-4 in mouse and human islets under conditions of obesity and type 2 diabetes. DPP-4 was expressed in islets of both species and in all models examined. Although DPP-4 activity in islets was lower than in plasma, it was clearly regulated in response to different metabolic conditions. In islets of obese mice chronically fed an HFD, DPP-4 activity was increased. In contrast, in human islets from type 2 diabetic donors, DPP-4 activity was decreased. In fact, there was a positive relationship between insulin secretion and DPP-4 activity in the human islets, and a trend in mouse islets, suggesting that insulin may play a role in regulating DPP-4 activity in human islets. Inhibition of DPP-4 in mouse and human islets resulted in a direct enhancement of insulin secretion itself in this study. Thus, DPP-4 is not only present and active in mouse and human islets, but inhibition of islet DPP-4 activity also has a direct stimulatory effect on insulin secretion, which is GLP-1 dependent.

The first demonstration of DPP-4 expression in islets was in pigs, showing exclusive expression in the alpha cells [25, 26]. To our knowledge the protein localisation of DPP-4 has not previously been shown in mouse or human islets. Mouse islets showed a near-exclusive expression of DPP-4 in beta cells, with little expression in alpha cells. Human islets were the opposite and, like pig islets, expressed DPP-4 almost exclusively in alpha cells. The species difference in the localisation of DPP-4 expression, and the possible physiological consequence of that difference, is unclear. Rodent and human islets differ somewhat in the distribution of islet cells, as well as in their vascularisation and innervation [27]. The species specificity of DPP-4 cellular localisation requires further investigation in other species and will be addressed in future studies.

In both the mouse and human pancreatic sections, there was a granular distribution of DPP-4 staining, suggesting that DPP-4 is secreted into the intracellular space as suggested in the earlier pig studies [25]. Shah and colleagues recently demonstrated that DPP-4 activity was detectable in the media of human islet incubations and that this activity was inhibited by the DPP-4 inhibitor, linagliptin, suggesting that it is secreted from human islets as well [28].

Previous studies have suggested that locally produced and secreted GLP-1 from rodent and human islets exerts beneficial effects on beta cell development, function and protection [28, 29]. Some of these studies demonstrated increased islet GLP-1 in diabetic states and suggested increased prohormone convertase $1 / 3(\mathrm{PC} 1 / 3)$ expression as the primary regulator of islet GLP-1 [10, 11, 13]. We confirm that GLP-1 is present in the islets in our study and demonstrate this for the first time in diet-induced obese mice and glucagon receptor knockout mice. While GLP-1 will not be produced in alpha cells in appreciable amounts without increased PC1/3 expression and activity, the functional effects of GLP-1 are dependent on the peptide reaching its receptor in its intact form. The tight spatial relationship between alpha and beta cells means that the intact GLP-1 secreted from alpha cells should reach the adjacent beta cells and act in a paracrine manner. This would be the case unless DPP-4 was secreted into the space between alpha and beta cells. Hence, the local production of GLP-1 and DPP4 may be tightly regulated and of relevance for islet function.

Interestingly, we demonstrate that human islets from type 2 diabetic patients have decreased DPP-4 activity. This corresponded to higher secretion of intact GLP-1 from the islets in overnight culture. Not only does the islet respond to the diabetic milieu by increasing PC1/3 expression, and thereby GLP-1 production, it also concurrently decreases DPP-4 activity to preserve the GLP-1 that is being produced in larger amounts. Therefore decreased DPP-4 activity and increased PC1/3 expression may both contribute to the increased secretion of intact GLP-1 seen in type 2 diabetic human islets. This implies that endogenous islet GLP-1 may play a functional role in diabetes.

Liu et al demonstrated that the chemokine, stromal cellderived factor-1 (SDF-1), increases GLP-1 production from islets [29]. SDF-1 was shown to be produced by beta cells and is itself a substrate for DPP-4, as demonstrated in vitro and in vivo [30]. In this case, a decrease in DPP-4 activity within the islet would result in more intact forms of SDF-1, which would in turn help drive further GLP-1 production from the islet. Other substrates of DPP-4 that have been shown to be expressed in islets include GIP, interferon $\gamma$ inducible protein 10 (IP-10) and pituitary adenylate cyclase-activating polypeptide (PACAP) [31-33]. It remains to be determined what effect the decrease in DPP-4 activity seen in islets from type 2 diabetic patients has on the resulting action of these substrates.

Inhibitors of DPP-4 are now established as effective treatments for type 2 diabetes [6]. Our results suggest that DPP-4 inhibitors can exert direct, GLP-1-dependent, effects on target tissues independent of plasma DPP-4 activity. This has been previously demonstrated in vivo by Waget and colleagues [7] using the DPP-4 inhibitor, sitagliptin, confirmed by our group with vildagliptin [34], and shown in vitro in human islets using the DPP-4 inhibitor, linagliptin [28]. Human islets from non-diabetic donors that had been incubated under hyperglycaemic-hyperlipidaemic conditions showed increased secretion of insulin and intact GLP-1, as well as reduced beta cell apoptosis, when treated with linagliptin [28]. There are numerous DPP-4 inhibitors used in clinical practice, and, although they all function to inhibit the 
peptidase activity of DPP-4, they are not all the same in their pharmacokinetic and pharmacodynamic profiles. Linagliptin and vildagliptin differ in their pharmacokinetic and pharmacodynamic properties. Vildagliptin forms covalent bonds with DPP-4 and is itself metabolised by DPP-4 [35], while linagliptin is a competitive DPP-4 inhibitor which does not covalently bond with DPP-4. With these differences, it stands to reason that different DPP-4 inhibitors have different tissuespecific effects.

An intriguing finding of this study is the positive correlation between DPP-4 activity in the islet and insulin secretion. It is logical that, if production of GLP-1 within alpha cells increases in islets of type 2 diabetic individuals, as has been demonstrated [13], a decrease in islet DPP-4 activity would result in more intact GLP-1 secreted from the alpha cell being able to act on its receptor. The correlation suggests that DPP-4 activity declines as beta cell function declines. One could speculate that insulin provides some measure of regulation of DPP-4 activity and, as tonic insulin secretion decreases, DPP-4 activity decreases with it. Conversely, in insulinresistant individuals who adequately compensate by increasing insulin secretion, increased insulin action on the beta cell may increase DPP-4 activity. The regulation of DPP-4 by insulin and the change in DPP-4 activity over the natural history of diabetes will need to be determined. This is the subject of ongoing studies.

In summary, DPP-4 is present in isolated islets from mice and humans, and its activity changes under different pathophysiological conditions. DPP-4 inhibitors exert direct effects on secretion of insulin and intact GLP-1 and thus may promote islet function in part by acting directly on islet DPP-4.

Acknowledgements The authors acknowledge K. Andersson, M. Anderberg and L. Ohlsson of the Department of Clinical Sciences, Lund University, Lund, Sweden for technical assistance, and U. Krus and A. Nilsson of the Lund University Diabetes Center Human Tissue Laboratory, Malmö, Sweden and the Nordic Network for Clinical Islet Transplantation, Uppsala University, Uppsala, Sweden for provision of the human islets and associated information. The authors thank E. Zhang of the Department of Clinical Sciences, Lund University, Malmö, Sweden for assistance with the confocal microscopy. The authors also acknowledge L. Marselli of the Department of Endocrinology and Metabolism, University of Pisa, Pisa, Italy for the provision of the human pancreatic tissue sections.

Funding This work was supported by grants from the Swedish Research Council, Lund University Medical Faculty, ALF/Region Skåne, Knut and Alice Wallenberg Foundation (confocal microscope) and the Royal Physiographical Society of Lund.

Duality of interest BA is a member of Novartis' speaker's bureau. All other authors declare that there is no duality of interest associated with their contribution to this manuscript.

Contribution statement LL designed and performed experiments, analysed data, wrote the manuscript and approved the final version. YY and YS provided experimental material and conceptual design, revised the manuscript and approved the final version. PM provided conceptual design and experimental material and revised and approved the final version of manuscript. BAO designed the study, performed experiments, analysed data, wrote the manuscript and approved the final version. BA designed the study, analysed data, wrote and revised the manuscript and approved the final version, and is the guarantor of this work.

\section{References}

1. Vilsboll T, Krarup T, Sonne J et al (2003) Incretin secretion in relation to meal size and body weight in healthy subjects and people with type 1 and type 2 diabetes mellitus. J Clin Endocrinol Metab 88:27062713

2. Meier JJ, Nauck MA, Kranz D et al (2004) Secretion, degradation, and elimination of glucagon-like peptide 1 and gastric inhibitory polypeptide in patients with chronic renal insufficiency and healthy control subjects. Diabetes 53:654-662

3. Deacon CF, Nauck MA, Toft-Nielsen M, Pridal L, Willms B, Holst JJ (1995) Both subcutaneously and intravenously administered glucagon-like peptide I are rapidly degraded from the NH2terminus in type II diabetic patients and in healthy subjects. Diabetes 44:1126-1131

4. Duke-Cohan JS, Morimoto C, Rocker JA, Schlossman SF (1995) A novel form of dipeptidylpeptidase IV found in human serum. Isolation, characterization, and comparison with $\mathrm{T}$ lymphocyte membrane dipeptidylpeptidase IV (CD26). J Biol Chem 270:14107-14114

5. Migoya EM, Bergeron R, Miller JL et al (2010) Dipeptidyl peptidase4 inhibitors administered in combination with metformin result in an additive increase in the plasma concentration of active GLP-1. Clin Pharmacol Ther 88:801-808

6. Deacon CF, Mannucci E, Ahren B (2012) Glycaemic efficacy of glucagon-like peptide-1 receptor agonists and dipeptidyl peptidase-4 inhibitors as add-on therapy to metformin in subjects with type 2 diabetes: a review and meta analysis. Diabetes Obes Metab 14:762767

7. Waget A, Cabou C, Masseboeuf M et al (2011) Physiological and pharmacological mechanisms through which the DPP-4 inhibitor sitagliptin regulates glycemia in mice. Endocrinology 152:30183029

8. Fujiwara K, Gotoh K, Chiba S et al (2012) Intraportal administration of DPP-IV inhibitor regulates insulin secretion and food intake mediated by the hepatic vagal afferent nerve in rats. J Neurochem 121: 66-76

9. Heller RS, Aponte GW (1995) Intra-islet regulation of hormone secretion by glucagon-like peptide-1-(7-36) amide. Am J Physiol 269:G852-G860

10. Kilimnik G, Kim A, Steiner DF, Friedman TC, Hara M (2010) Intraislet production of GLP-1 by activation of prohormone convertase $1 / 3$ in pancreatic alpha-cells in mouse models of ss-cell regeneration. Islets 2:149-155

11. Hansen AM, Bodvarsdottir TB, Nordestgaard DN et al (2011) Upregulation of alpha cell glucagon-like peptide 1 (GLP-1) in Psammomys obesus: an adaptive response to hyperglycaemia? Diabetologia 54:1379-1387

12. Ellingsgaard H, Hauselmann I, Schuler B et al (2011) Interleukin-6 enhances insulin secretion by increasing glucagon-like peptide-1 secretion from $L$ cells and alpha cells. Nat Med 17:1481-1489

13. Marchetti P, Lupi R, Bugliani M et al (2012) A local glucagon-like peptide 1 (GLP-1) system in human pancreatic islets. Diabetologia 55:3262-3272

14. Li T, Bai L, Li J, Igarashi S, Ghishan FK (2008) Sp1 is required for glucose-induced transcriptional regulation of mouse vesicular glutamate transporter 2 gene. Gastroenterology 134:1994-2003 
15. Gelling RW, Du XQ, Dichmann DS et al (2003) Lower blood glucose, hyperglucagonemia, and pancreatic alpha cell hyperplasia in glucagon receptor knockout mice. Proc Natl Acad Sci U S A 100: 1438-1443

16. Hansotia T, Baggio LL, Delmeire D et al (2004) Double incretin receptor knockout (DIRKO) mice reveal an essential role for the enteroinsular axis in transducing the glucoregulatory actions of DPP-IV inhibitors. Diabetes 53:1326-1335

17. Johansson U, Olsson A, Gabrielsson S, Nilsson B, Korsgren O (2003) Inflammatory mediators expressed in human islets of Langerhans: implications for islet transplantation. Biochem Biophys Res Commun 308:474-479

18. Taneera J, Lang S, Sharma A et al (2012) A systems genetics approach identifies genes and pathways for type 2 diabetes in human islets. Cell Metab 16:122-134

19. Krus U, King BC, Nagaraj V et al (2014) The complement inhibitor CD59 regulates insulin secretion by modulating exocytotic events. Cell Metab 19:883-890

20. Olsson A, Johansson U, Korsgren O, Frisk G (2005) Inflammatory gene expression in Coxsackievirus B-4-infected human islets of Langerhans. Biochem Biophys Res Commun 330:571-576

21. Berg AK, Korsgren O, Frisk G (2006) Induction of the chemokine interferon-gamma-inducible protein-10 in human pancreatic islets during enterovirus infection. Diabetologia 49:2697-2703

22. Gunnarsson PT, Winzell MS, Deacon CF et al (2006) Glucoseinduced incretin hormone release and inactivation are differently modulated by oral fat and protein in mice. Endocrinology 147: 3173-3180

23. Omar BA, Andersen B, Hald J, Raun K, Nishimura E, Ahren B (2014) Fibroblast growth factor 21 (FGF21) and glucagon-like peptide 1 contribute to diabetes resistance in glucagon receptor-deficient mice. Diabetes 63:101-110

24. Serre V, Dolci W, Schaerer E et al (1998) Exendin-(9-39) is an inverse agonist of the murine glucagon-like peptide-1 receptor: implications for basal intracellular cyclic adenosine $3^{\prime}, 5^{\prime}$ monophosphate levels and beta-cell glucose competence. Endocrinology 139:4448-4454
25. Poulsen MD, Hansen GH, Dabelsteen E, Hoyer PE, Noren O, Sjostrom H (1993) Dipeptidyl peptidase IV is sorted to the secretory granules in pancreatic islet A-cells. J Histochem Cytochem 41:81-88

26. Grondin G, Hooper NM, LeBel D (1999) Specific localization of membrane dipeptidase and dipeptidyl peptidase IV in secretion granules of two different pancreatic islet cells. J Histochem Cytochem 47:489-498

27. Chiu YC, Hua TE, Fu YY, Pasricha PJ, Tang SC (2012) 3-D imaging and illustration of the perfusive mouse islet sympathetic innervation and its remodelling in injury. Diabetologia 55:3252-3261

28. Shah P, Ardestani A, Dharmadhikari G et al (2013) The DPP-4 inhibitor linagliptin restores beta-cell function and survival in human isolated islets through GLP-1 stabilization. J Clin Endocrinol Metab 98:E1163-E1172

29. Liu Z, Stanojevic V, Avadhani S, Yano T, Habener JF (2011) Stromal cell-derived factor-1 (SDF-1)/chemokine (C-X-C motif) receptor 4 (CXCR4) axis activation induces intra-islet glucagon-like peptide-1 (GLP-1) production and enhances beta cell survival. Diabetologia 54: 2067-2076

30. Mentlein R (1999) Dipeptidyl-peptidase IV (CD26): role in the inactivation of regulatory peptides. Regul Pept 85:9-24

31. Fujita Y, Wideman RD, Asadi A et al (2010) Glucose-dependent insulinotropic polypeptide is expressed in pancreatic islet alpha-cells and promotes insulin secretion. Gastroenterology 138:1966-1975

32. Schulthess FT, Paroni F, Sauter NS et al (2009) CXCL10 impairs beta cell function and viability in diabetes through TLR4 signaling. Cell Metab 9:125-139

33. Fridolf T, Sundler F, Ahren B (1992) Pituitary adenylate cyclase-activating polypeptide (PACAP): occurrence in rodent pancreas and effects on insulin and glucagon secretion in the mouse. Cell Tissue Res 269:275-279

34. Omar B, Ahren B (2014) Pleiotropic mechanisms for the glucoselowering actions of DPP-4 inhibitors (in press)

35. Ahren B, Schweizer A, Dejager S, Villhauer EB, Dunning BE, Foley JE (2011) Mechanisms of action of the dipeptidyl peptidase-4 inhibitor vildagliptin in humans. Diabetes Obes Metab 13:775-783 